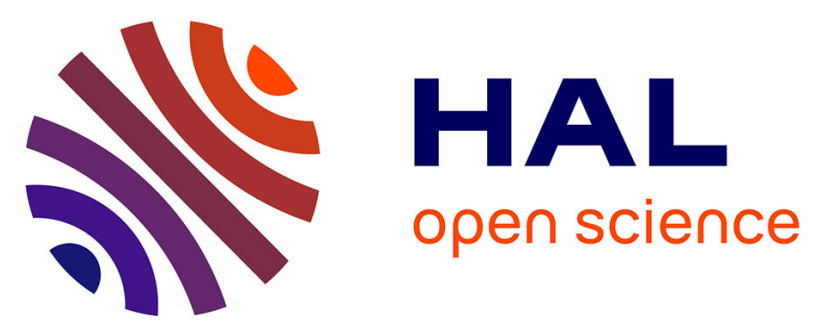

\title{
$\pi$-electron content of rings in polycyclic conjugated compounds - A valence bond based measure of local aromaticity
}

Slavko Radenković, Marija Antić, Slađana Đorđević, Benoît Braïda

\section{- To cite this version:}

Slavko Radenković, Marija Antić, Slađana Đorđević, Benoît Braïda. $\pi$-electron content of rings in polycyclic conjugated compounds - A valence bond based measure of local aromaticity. Computational and Theoretical Chemistry, 2017, 1116, pp.163-173. 10.1016/j.comptc.2017.01.028 . hal-01627695

\section{HAL Id: hal-01627695 \\ https://hal.science/hal-01627695}

Submitted on 21 Nov 2017

HAL is a multi-disciplinary open access archive for the deposit and dissemination of scientific research documents, whether they are published or not. The documents may come from teaching and research institutions in France or abroad, or from public or private research centers.
L'archive ouverte pluridisciplinaire HAL, est destinée au dépôt et à la diffusion de documents scientifiques de niveau recherche, publiés ou non, émanant des établissements d'enseignement et de recherche français ou étrangers, des laboratoires publics ou privés. 


\title{
$\pi$-electron content of rings in polycyclic conjugated compounds - A valence bond based measure of local aromaticity
}

\author{
Slavko Radenković ${ }^{\mathrm{a}, *}$, Marija Antić ${ }^{\mathrm{a}}$, Slađana Đorđevićc ${ }^{\mathrm{a}}$, Benoît Braïda ${ }^{\mathrm{b}, *}$ \\ ${ }^{a}$ University of Kragujevac, Faculty of Science, P.O. Box 60, 34000 Kragujevac, Serbia \\ ${ }^{\mathrm{b}}$ Sorbonne Universités, UPMC Univ Paris 06, CNRS, Laboratoire de Chimie Théorique, cc 137 - 4, place Jussieu, F. 75252 Paris Cedex 05, France
}

\section{Keywords:}

Valence-Bond Theory

Aromaticity

Polycyclic aromatic hydrocarbons

Kekulé structures

\begin{abstract}
A B S T R A C T
In 2004 Randić and Balaban employed Kekulé structures to assess the $\pi$-electron content (EC) of rings in benzenoid hydrocarbons. In this paper we showed how ab initio Valence Bond (VB) calculations based on the set of Kekulé structures of a given polycyclic conjugated molecule can be used to obtain more accurate $\pi$-electron contents of rings $(V B-E C)$ as the true computed weights of the Kekule structures are used, instead of postulating that all Kekulé structures have equal weights as in the $E C$ formula. In the case of benzenoid hydrocarbons, the values of $V B-E C$ and $E C$ are very close. The main difference is found for linear polyacenes, for which, contrary to the $E C$, the $V B-E C$ values predict that the inner rings are more aromatic than the terminal rings. The original EC method has also the disadvantage that it cannot be applied to heterocyclic conjugated molecules. It was shown that the $V B-E C$ method can be used to assess the local aromaticity in aza derivatives of naphthalene. The calculated $V B-E C$ values were compared with several other aromaticity indices, namely: energy effect (ef), harmonic oscillator model of aromaticity (HOMA) index, six center delocalization index $(S C I)$ and nucleus independent chemical shifts (NICS). The best correlation was found between the VB-EC and SCI, implying that these two indices carry similar information on the local aromaticity.
\end{abstract}

\section{Introduction}

Aromaticity is among the most important concepts in chemistry [1-3]. It is closely related to cyclic electrons delocalization that provides extra stability to molecular systems. The quantitative measure of the stabilizing effect caused by cyclic electrons delocalization is the resonance energy. The concept of resonance was put forward by Pauling and Wheland within the framework of Valence Bond (VB) theory [4]. Later, various other approaches were also introduced to calculate the resonance energy. Among the most employed, one can find: Dewar's method [5], Hess-Schaad's method [6], graph theoretical method [7,8], Randić's conjugated circuits method [9], Herndon's semi-empirical VB method $[10,11]$, and the block-localized wave function method [12-14]. Aromaticity is not an observable or directly measurable quantity, and therefore this concept has no unique definition $[1,9]$. There is a series of different criteria of aromaticity, namely energetic [1], electron delocalization [2,3], geometric [1,15,16], magnetic $[17,18]$ and reactivity based criteria [19]. Resonance energy and

* Corresponding authors.

E-mail addresses: slavkoradenkovic@kg.ac.rs (S. Radenković), benoit.braida @upmc.fr (B. Braïda). more generally the aromatic stabilization energy [1] are widely accepted energetic criteria to measure aromaticity. The choice of the appropriate reference system is crucial in calculations of the energetic aromaticity indices. Even for benzene, as a prototype aromatic molecule, there is a lot of controversy about its resonance energy [20-22]. Although the concept of resonance energy originates from Valence Bond theory, nowadays most of the employed aromaticity indices are obtained using MO and DFT calculations.

The central concept of VB methods $[23,24]$ is to construct and compute a wavefunction, for a given molecular system, that is a linear combination of VB structures each of which maps to a corresponding Lewis structure. As a consequence, the concept of resonance is deeply rooted into $\mathrm{VB}$ theory. In the case of polycyclic aromatic hydrocarbons (PAHs), it is well known that their electronic and physical properties can be sufficiently described, at least at a qualitative and semi-quantitative level, by the corresponding set of Kekulé structures [25]. Kekulé structures have been a subject of interest for theoretical chemists for more than a century. There are several theories based on the Kekule structures which have been successfully applied in different fields of PAH chemistry. Among the most influential ones are: Clar's aromatic sextet theory $[26,27]$, Randić's conjugated circuit theory [9], the partition of 
$\pi$-electrons into rings [28,29], Kekulé structures based ring currents [30] and the topological index of reactivity [19].

In 2004 Randić [31] put forward a concept of the so-called "algebraic Kekulé structures". The algebraic Kekulé structures are obtained from the regular Kekule structures by counting the number of $\pi$-electrons which belong to each ring of the considered benzenoid molecule. In the given Kekule structure, double bonds shared by two rings are assumed to contribute to one $\pi$-electron to each ring, whereas other double bonds contribute through both of their $\pi$-electrons to the ring they belong to. An example, illustrating the construction of the algebraic Kekule structures, is given in Fig. 1. It has been shown that, in the case of catacondensed benzenoid molecules, there is a one-to-one correspondence between ordinary and algebraic Kekulé structures [32]. The algebraic Kekulé structures were further employed to assess the $\pi$-electron contents of rings in benzenoid hydrocarbons $[28,29]$.

In the present paper we show how VB calculations based on the set of Kekule structures can be used to obtain the local aromaticity distribution in a series of polycyclic aromatic compounds (Fig. 2). As seen from Fig. 2, all planar catacondensed benzenoid hydrocarbons with 3,4 and 5 hexagons, as well as all non-symmetrical monoaza and diaza naphthalene derivatives (a total of 22 molecules, 59 symmetry-non-equivalent hexagonal rings) were considered. The results obtained using VB calculations were compared with the several different indices of aromaticity, namely the energy effect (ef) [33,34], the harmonic oscillator model of aromaticity (HOMA) index [15,35], the six center delocalization index $(S C I)[36,37]$ and the nucleus independent chemical shifts (NICS) [17,38].

\section{Methodology}

\subsection{VB theory}

The wave function $|\Psi\rangle$ of a given molecular system in VB theory is expressed as a linear combination of VB structures:

$|\Psi\rangle=\sum_{I} C_{I} \Phi_{I}$

with each structure being a spin-adapted determinant or combination of determinants, also called Heitler-London-Slater-Pauling
(HLSP) functions, that maps with a specific Lewis (here Kekulé) structure. In most applications, the VB orbitals on which the determinants are built separate into one or several active and inactive sets of orbitals. In this work, the $\sigma$ orbitals are inactive and described by delocalized MO, i.e. they are allowed to expand onto the whole basis of functions (compatible with the $\sigma$ symmetry), whereas the $\pi$ orbitals are taken as active and are only allowed to expand on $\pi$-type basis functions that are centered on one specific atom only. Such orbitals are usually referred to as Hybrid Atomic Orbitals (HAOs). These constraints of strict localization of active orbitals therefore imply to use non-orthogonal VB orbitals. Such VB wave functions where the active orbitals are strictly localized belongs to the "classical VB" branch of Valence Bond theory $[23,24]$. In the present work, the VB Self-Consistent-Field (VBSCF) method was used, in which a common set of orbitals are used for all VB structures, and both the VB orbital coefficients onto the basis of functions and the structural coefficients are optimized simultaneously to minimize the total energy. The VBSCF method is thus the equivalent of the MCSCF method in MO theory.

In order to test the quality of VBSCF wave functions that include only a small selection of covalent structures (only the Kekule type of structures), some calculations have also been performed with the same selection of structures, but using Overlap Enhanced Orbitals (OEOs) in place of HAOs. The OEOs are obtained starting from a converged set of HAOs (and delocalized inactive) orbitals, and allowing both all active and inactive orbitals to expand onto the whole basis of functions. In practice, OEOs obtained this way remain essentially localized on one atom, but with small delocalization tails over all other atoms (mainly the close neighbors) in the molecule, so that to implicitly account for some missing spin-coupling and missing ionic structures. Using OEOs thus allows a great deal of static correlation to be included while still using a limited selected set of formally covalent structures. Note that the VB wave function including a complete set of covalent structures (all possible spin-couplings) in conjunction with OEOs is usually referred to as the Spin-Coupled (or full Generalized Valence Bond) wave function.

The VB structures weights are not unique, and thus different definitions have been proposed [23,24]. The most commonly used is the Coulson-Chirgwin formula [39], which is the equivalent of the Mulliken population analysis for structure weights:<smiles>c1ccc2c(c1)ccc1ccccc12</smiles><smiles>c1ccc2c(c1)ccc1ccccc12</smiles><smiles>c1ccc2c(c1)ccc1ccccc12</smiles><smiles>C1CCC2C(C1)CCC1CCCCC12</smiles>

$\mathrm{k}_{3}$<smiles>c1ccc2c(c1)ccc1ccccc12</smiles><smiles>c1ccc2c(c1)ccc1ccccc12</smiles><smiles>C1CCC2C(C1)CCC1CCCCC12</smiles>

$\mathrm{k}_{4}$

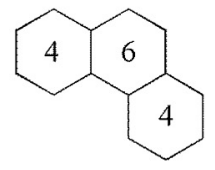

$\mathrm{k}_{5}$

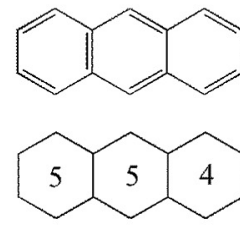

$\mathrm{k}_{1}$
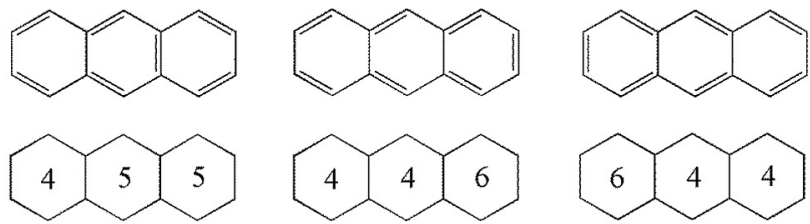

$\mathrm{k}_{2}$

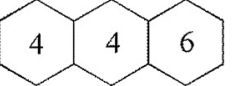

$\mathrm{k}_{3}$

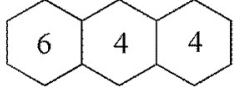

$\mathrm{k}_{4}$

Fig. 1. Kekulé structures and algebraic Kekulé structures of phenanthrene and anthracene. 

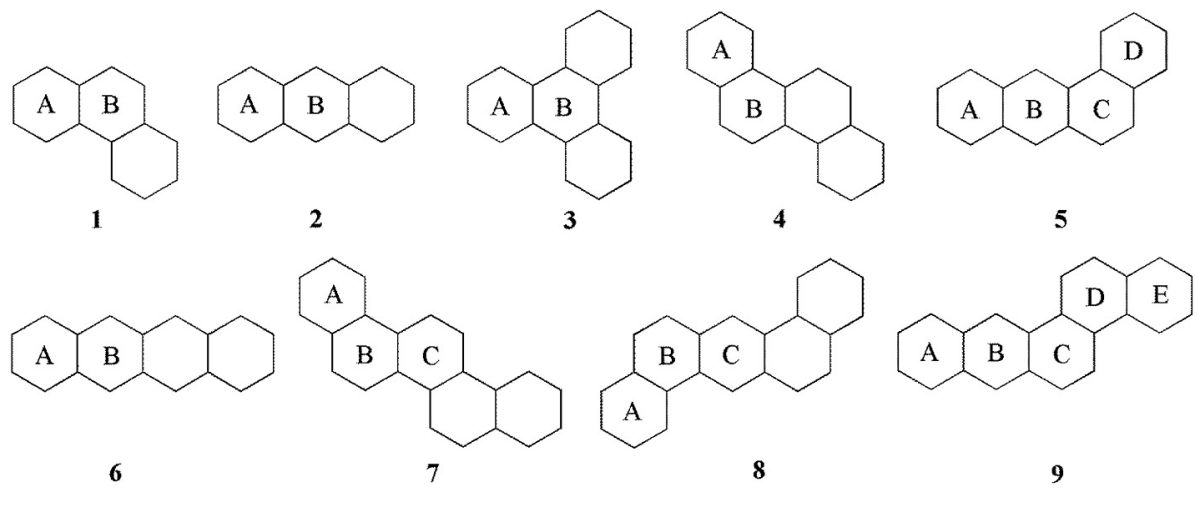

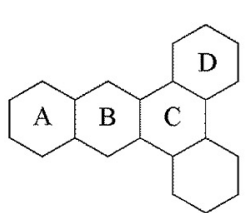

10

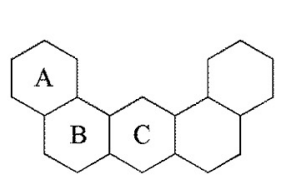

11

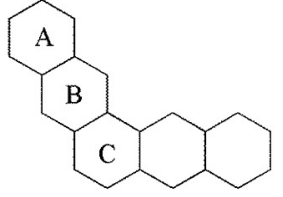

12

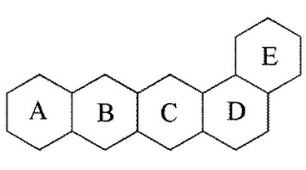

13<smiles></smiles>

14

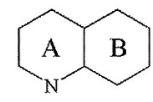

15

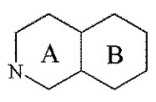

16

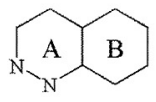

17

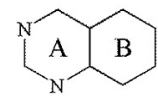

18

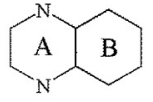

19

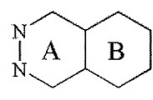

20

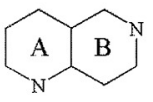

21

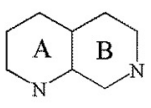

22

Fig. 2. Set of polycyclic conjugated molecules studied with the molecular nomenclature employed; symmetry unique rings are denoted by capital letters.

$W_{I}^{C C}=C_{I}^{2}+\sum_{J=1}^{N} C_{I} C_{J} S_{I J}$

where $S_{I J}$ is the overlap integral of two VB structures. Although the Coulson-Chirgwin weights are standard, in the case of large overlap this definition becomes meaningless, and sometimes small contributors may come out with negative weights. In order to overcome this issue, one may use the Löwdin scheme [40]:

$W_{I}^{\text {Lowdin }}=\sum_{J, L} S_{I J}^{1 / 2} C_{J} S_{I L}^{1 / 2} C_{L}$

Lowdin formula often leads to larger weights for the minor structures as compared with other formula. Another proposition is the inverse-overlap weights, which can be calculated by means of the Norbeck-Gallup formula [41]:

$W_{I}^{\text {Inverse }}=\frac{N C_{I}^{2}}{S_{I I}^{-1}}$

Last, to circumvent the overlap issue, the simple renormalized (Hiberty) weights may also be used:

$W_{I}^{\text {Renorm }}=N C_{I}^{2}$

where $N$ stands in each case for the appropriate normalization factors, that leads to weights which sums to 1 .

\subsection{The EC and VB-EC formulas}

In the present paper a new measure of local aromaticity based on $a b$ initio VB calculations is proposed. The VB-based $\pi$-electron content $(V B-E C(R))$ of a ring $R$ is defined as follows:

$V B-E C(R)=\sum_{k=1}^{K} W_{k} \cdot E C(R, k)$

where $K$ is the total number of Kekule structures, $E C(R, k)$ is the number of $\pi$-electron in ring $R$ of the given Kekule structure $k$ whose VB weight is $W_{k}$, and summation goes over all Kekulé structures. The $E C(R, k)$ numbers for a given molecule can be obtained by constructing the so-called algebraic Kekule structures, as mentioned in the Introduction section. It should be noted that the $\pi$-electron content, $E C(R)$ was originally introduced by Randić and Balaban $[28,29]$. One can immediately recognize that our approach is equivalent to the Randić-Balaban method, i.e.:

$V B-E C(R)=E C(R)$

if all Kekulé structures are equally weighted:

$W_{k}=\frac{1}{K} \quad$ for $\quad k=1,2, \ldots, K$.

It has been shown [42] that the Randić-Blaban $E C(R)$ values can be expressed in terms of the Pauling bond order [43]: 
$E C(R)=\sum_{r s} b_{r s} \cdot P_{r s}^{P}$

where the summation goes over all $r s$ bonds in the given ring $R$, $b_{r s}=2$ if $r$ s bond solely belongs to ring $R$ or $b_{r s}=1$ if $r$ s bond is shared between ring $R$ and another ring. Recall that the Pauling bond order is defined as:

$P_{r s}^{P}=\frac{K_{r s}}{K}$

where $K_{r s}$ is the number of Kekule structures in which the bond $r s$ is double. Assuming that

$\sum_{k=1}^{K} W_{k}=1$,

the bond order of the given $r$ carbon-carbon bond can be defined in a more general way as

$P_{r s}^{V B}=\sum_{k=1}^{K} \delta_{k}^{r s} W_{k}$

where $\delta_{k}^{r s}$ is 1 if the $r s$ bond is double in Kekule structure $k$, and 0 otherwise. Evidently, the Pauling bond order is a special case of $P_{r s}^{V B}$ where all Kekulé structures have the same weight as given by Eq. (8). It can be easily shown that:

$V B-E C(R)=\sum_{r s} b_{r s} \cdot P_{r s}^{V B}$

where the summation goes over all $r$ s bonds in the given ring $R$, with $b_{r s}=2$ if $r s$ bond solely belongs to ring $R$ or $b_{r s}=1$ if $r s$ bond is shared between ring $R$ and another ring. Another basic property of $V B-E C(R)$ can be immediately recognized:

$\sum_{R} V B-E C(R)=n_{\pi}$

where $n_{\pi}$ is the number of $\pi$-electrons of the given polycyclic conjugated system, and summation goes over all rings.

\subsection{Delocalization and aromaticity indices}

The energy effect of a given cycle $Z(e f(Z))[33,34]$ is defined as the difference between the total $\pi$-electron energy and an appropriate reference energy in which the contributions coming from the given cycle are neglected, whereas contributions coming from any other structural feature are taken into account. Within the framework of chemical graph theory the $e f(Z)$ can be calculated as follows:

ef $(Z)=\frac{2}{\pi} \int_{0}^{\infty} \ln \left|\frac{\phi(G, i x)}{\phi(G, i x)+2 \phi(G-Z, i x)}\right| d x$

where $G$ is the molecular graph representing the $\pi$-electron system considered, $\phi(G, x)$ is its characteristic polynomial, and $G-Z$ is the subgraph obtained by deleting the cycle $Z$ from $G$.

The multicentre delocalization indices quantify electron delocalization among a given set of atoms [3]. Using the Mulliken partition scheme, the six centre index $(S C I)$ can be calculated as follows [36,37]:

$S C I=\frac{1}{32} \sum_{\mu \in A} \sum_{v \in B} \sum_{\sigma \in C} \cdots \sum_{\xi \in F} \sum_{i=1}^{6 !} \Gamma_{i}\left[(P S)_{\mu v}(P S)_{v \sigma} \cdots(P S)_{\xi \mu}\right]$

where $P$ is the density matrix and $S$ is the overlap matrix. The summation goes over all basis functions $\mu, v, \sigma, \ldots, \xi$ centred on the atoms $A-F$ involved in a given six-membered ring, and $\widehat{\Gamma}_{i}$ is the permutation operator which for the given set of six basis functions $\mu, v, \sigma, \ldots, \xi$ produces all possible permutations (in total 6 ! permu- tations). The multicentre delocalization indices can be calculated using different partition schemes [44-46]. In this work, the natural atomic orbital (NAO) density matrices obtained from NBO analysis [47] were also used to calculate the six centre index $\left(S C I^{N A O}\right)$. Note that the NAOs are orthonormal (the overlap matrix is a unit matrix) and calculations of $S C I^{N A O}$ are solely based on the NAO density matrix (cf. Eq. (16)).

The harmonic oscillator model of aromaticity (HOMA) index is the geometry-based measure of aromaticity. The HOMA index is calculated as [15,35]:

$H O M A=1-\frac{1}{n} \sum_{i=1}^{n} \alpha\left(R_{o p t}-R_{i}\right)^{2}$

where $n$ is the number of bonds of the ring considered, $\alpha$ is a normalization constant, $R_{\text {opt }}$ is the optimal bond length for a fully delocalized $\pi$-electron system, and $R_{i}$ stands for an actual bond length. In the present study the parameters proposed by Krygowski were used [15]: $\alpha_{C C}=257.7, \alpha_{C N}=93.52, \alpha_{N N}=130.33, R_{o p t}^{C C}=1.388$, $R_{\text {opt }}^{C N}=1.334$ and $R_{o p t}^{N N}=1.309$.

The nucleus independent chemical shift (NICS) index is among the most popular aromaticity indices [17]. Originally, the NICS was defined as the negative value of the isotropic shielding constant calculated at the ring centre. The NICS is a tensor, and different components of the tensor calculated at different positions of a considered system can be used as appropriate indices of aromaticity. In the present study, NICS calculated $1 \AA$ above the ring centre (NICS(1)) was employed.

\subsection{Computational details}

Geometries of the studied molecules (Fig. 2) were optimized by means of the B3LYP/6-311G(d,p) method using the Gaussian 09 program [48]. NICS were calculated through the gauge-including atomic orbital (GIAO) method $[49,50]$ at the same level of theory. The B3LYP/6-311G(d,p) optimized structures were employed for the HOMA indices calculations. The Mulliken based SCI were calculated from the B3LYP/6-311G(d,p) density matrices, whereas the $S C I^{N A O}$ were calculated from the NAO density matrices obtained from NBO analysis as implemented in Gaussian 09 program.

The weights of Kekule structures needed for calculations of the $V B-E C$ values were obtained from the VBSCF wave functions. For all the studied benzenoid molecules (1-14) the minimal basis set (STO-6G) was used in combination with strictly localized hybrid atomic orbitals (HAOs). In the case of benzenoids with 5 hexagons (7-14) the core-frozen approximation was employed, in which the core orbitals were taken from Hartree-Fock calculations without further optimization. To check the sustainability of the results obtained with the STO-6G basis set, the VBSCF calculations for anthracene and phenanthrene were carried out using the $6-311 \mathrm{C}$ $(\mathrm{d}, \mathrm{p})$ basis set. Besides, for these two molecules the VB weights obtained with HAOs were compared with the ones obtained with the overlap enhanced orbitals (OEOs), which are mainly localized on one atom, but with small delocalized tails over all other atoms in the molecule (see Section 2.1 for more details). The weights of Kekulé structures for the studied benzenoid molecules $(\mathbf{1}-\mathbf{1 4})$ were also obtained using the so-called pseudo- $\pi$ method. In this approach carbon atoms are replaced by hydrogen atoms in the original carbon positions and the minimal basis set (STO-6G) is used in VBSCF calculations. It has been proved that the pseudo- $\pi$ method can provide the same essential information about the ring currents [51] and electron delocalization [52] in benzenoid hydrocarbons.

Due to their reasonably small size, for the studied aza naphthalene derivatives (15-22) the VBSCF calculations were performed with the 6-311G(d,p) basis set and HAOs. 
Table 1

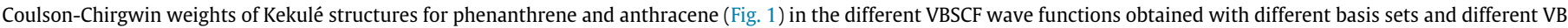
orbitals.

\begin{tabular}{|c|c|c|c|c|c|c|}
\hline \multirow[t]{2}{*}{ Phenanthrene } & \multicolumn{2}{|c|}{$6-311 G(d, p)$} & \multicolumn{2}{|l|}{ STO-6G } & \multicolumn{2}{|c|}{ Pseudo- $\pi$} \\
\hline & HAO & OEO & HAO & OEO & HAO & OEO \\
\hline $\mathrm{k}_{1}$ & 0.2970 & 0.4179 & 0.3018 & 0.3831 & 0.2763 & 0.3669 \\
\hline $\mathrm{k}_{2}$ & 0.2190 & 0.1910 & 0.2175 & 0.1991 & 0.2181 & 0.2016 \\
\hline $\mathrm{k}_{3}$ & 0.2190 & 0.1910 & 0.2175 & 0.1991 & 0.2181 & 0.2015 \\
\hline $\mathrm{k}_{4}$ & 0.1462 & 0.0803 & 0.1512 & 0.0975 & 0.1599 & 0.1021 \\
\hline $\mathrm{k}_{5}$ & 0.1189 & 0.1192 & 0.1120 & 0.1212 & 0.1277 & 0.1279 \\
\hline \multicolumn{7}{|l|}{ Anthracene } \\
\hline $\mathrm{k}_{1}$ & 0.3509 & 0.3580 & 0.3527 & 0.3522 & 0.3340 & 0.3460 \\
\hline $\mathrm{k}_{2}$ & 0.3509 & 0.3580 & 0.3527 & 0.3522 & 0.3340 & 0.3460 \\
\hline $\mathrm{k}_{3}$ & 0.1491 & 0.1421 & 0.1473 & 0.1478 & 0.1660 & 0.1540 \\
\hline $\mathrm{k}_{4}$ & 0.1491 & 0.1421 & 0.1473 & 0.1478 & 0.1660 & 0.1540 \\
\hline
\end{tabular}

Table 2

$V B-E C$ values for phenanthrene (1) and anthracene (2) obtained from the Kekulé structure weights given in Table 1, for the two symmetry unique rings A and B (see Fig. 2).

\begin{tabular}{|c|c|c|c|c|c|c|}
\hline \multirow[t]{2}{*}{ Phenanthrene } & \multicolumn{2}{|c|}{$6-311 G(d, p)$} & \multicolumn{2}{|l|}{ STO-6G } & \multicolumn{2}{|c|}{ Pseudo- $\pi$} \\
\hline & HAO & OEO & HAO & OEO & HAO & OEO \\
\hline A & 5.2462 & 5.1487 & 5.2568 & 5.1754 & 5.2503 & 5.1758 \\
\hline B & 3.5076 & 3.6926 & 3.4866 & 3.6492 & 3.4995 & 3.6484 \\
\hline \multicolumn{7}{|l|}{ Anthracene } \\
\hline A & 4.6490 & 4.6421 & 4.6473 & 4.6478 & 4.6660 & 4.6541 \\
\hline B & 4.7018 & 4.7159 & 4.7054 & 4.7044 & 4.6679 & 4.6920 \\
\hline
\end{tabular}

Table 3

$V B-E C$ values for 1 and 2 obtained with the VBSCF method using the $6-311 \mathrm{G}(\mathrm{d}, \mathrm{p})$ basis set and different $V B$ structure weight definitions, for the two symmetry unique rings A and B (see Fig. 2).

\begin{tabular}{llll}
\hline Phenanthrene & $W^{\text {Lowdin }}$ & $W^{\text {Inverse }}$ & $W^{\text {Renorm }}$ \\
\hline A & 5.2479 & 5.2178 & 5.2360 \\
B & 3.5042 & 3.5645 & 3.5284 \\
Anthracene & & & \\
A & 4.6517 & 4.7717 & 4.6383 \\
B & 4.6965 & 4.7766 & 4.7234 \\
\hline
\end{tabular}

All VB calculations were performed using the XMVB 2.1 program [53-56]. Calculations of SCI and ef were performed using our own Fortran routines.

\section{Results and discussion}

\subsection{Benzenoid hydrocarbons}

First the basis set dependence of the calculated $V B$-EC values was examined for phenanthrene (1) and anthracene (2). As seen from Eq. (6), calculations of the $V B-E C$ values are based on the VB weights of the corresponding Kekule structures. Table 1 contains the VBSCF Coulson-Chirgwin weights of Kekulé structures of $\mathbf{1}$ and $\mathbf{2}$ (Fig. 1) obtained using the 6-311G(d,p) and STO-6G basis set, as well as with the pseudo- $\pi$ approach. In addition, the Coulson-Chirgwin weights were obtained by two VB approaches differing by the type of VB orbitals, VB-HAO and VB-OEO. It can be observed that the values of the VB weights obtained with the minimal basis set, and even with the pseudo- $\pi$ approach are very similar to the ones obtained with the $6-311 \mathrm{G}(\mathrm{d}, \mathrm{p})$ basis set. In addition, for 2 the VB-HAO and VB-OEO weights are also very similar. In the case of $\mathbf{1}$, the VB-OEO approach gives a somewhat larger weight for the Kekulé structure $k_{1}$ in comparison with the VB-HAO results. The calculated $V B-E C$ values for $\mathbf{1}$ and 2 obtained with the Coulson-Chirgwin weights are presented in Table 2. As can be seen, small to moderate differences that can be found in the weights of Kekule structures (Table 1) resulted in insignificant differences between the $V B-E C$ values. Hence, the simplest pseudo- $\pi$ approach using HAOs provides very similar $V B-E C$ values when compared with the most accurate VB-OEO approach using the $6-311 \mathrm{G}(\mathrm{d}, \mathrm{p})$. The influence of different types of VB weights on the calculated $V B-E C$ values was also examined. Table 3 provides the $V B-E C$ values for $\mathbf{1}$ and $\mathbf{2}$ obtained with the Löwdin, inverseoverlap and renormalized weights for the corresponding Kekule structures, computed from the VBSCF/6-311G(d,p) wave functions. The values of the weights are given in the Supplementary material (Tables S1 and S2). From Table 3 it can be seen that only the inverse weight based $V B-E C$ values for 2 depart slightly (a bit more than 0.1 ) from the $V B-E C$ values obtained with other types of $V B$ weights. Anyway, all found differences in the $V B-E C$ values based on different $V B$ weight definitions describe the same local aromaticity distribution in the studied systems. Besides, there is a very good linear correlation between the Coulson-Chirgwin weight based $V B-E C$ values and $V B-E C$ obtained with other VB weights (Fig. S1 in the Supplementary material).

Bearing in mind these findings, all further discussion is based on the $V B-E C$ values obtained with the minimal basis set and the VBHAO Coulson-Chirgwin weights of Kekule structures. The calculated aromaticity indices for the studied benzenoids together with $V B-E C$ and $E C$ values are presented in Table 4. Fig. S2 (see Supplementary material) clearly confirm the almost perfect correlation, for the studied benzenoid molecules, between the $V B-E C$ values obtained with the minimal basis set and pseudo- $\pi$ technique (correlation coefficient is 0.9998 ). Considering the computational effort needed to obtain $V B-E C$ values for the real systems, in the case of large benzenoids the preference should be given to the pseudo- $\pi$ based $V B-E C$. As can be seen from Table 1, the computed weights for the different types of structures are far from equal, and at first sight the $E C$ can be considered as a crude approximation of the $V B$ $E C$ values. It is amazing, though, that for the studied benzenoid molecules the values of $V B-E C$ and $E C$ come out so close, with as the worst case a difference between these two quantities still smaller than 0.3 electrons. The correlation between $V B-E C$ and $E C$ is found to be linear, with the correlation coefficient as large as 0.9914 (Fig. 3). 
Table 4

ef, $S C I, S C I^{N A O}, H O M A, N I C S(1), E C, V B-E C, V B-E C^{*}$ of the symmetry-unique rings in the studied benzenoid hydrocarbons (Fig. 2).

\begin{tabular}{|c|c|c|c|c|c|c|c|c|c|}
\hline Comp. & Ring & $e f$ & $S C I$ & $S C I^{N A O}$ & HOMA & $\operatorname{NICS}(1)$ & $E C$ & $V B-E C^{\mathrm{a}}$ & $V B-E C^{* b}$ \\
\hline \multirow[t]{2}{*}{1} & A & 0.1586 & 0.0285 & 0.0317 & 0.8699 & -11.48 & 5.2000 & 5.2568 & 5.2503 \\
\hline & B & 0.0534 & 0.0110 & 0.0121 & 0.4611 & -9.08 & 3.6000 & 3.4866 & 3.4995 \\
\hline \multirow[t]{2}{*}{2} & A & 0.0951 & 0.0177 & 0.0198 & 0.6301 & -10.53 & 4.7500 & 4.6473 & 4.6660 \\
\hline & B & 0.0653 & 0.0169 & 0.0182 & 0.7224 & -13.77 & 4.5000 & 4.7054 & 4.6679 \\
\hline \multirow[t]{2}{*}{3} & A & 0.1910 & 0.0316 & 0.0349 & 0.9027 & -10.56 & 5.3333 & 5.3656 & 5.3614 \\
\hline & B & 0.0242 & 0.0053 & 0.0056 & 0.1000 & -6.06 & 2.0000 & 1.9034 & 1.9158 \\
\hline \multirow[t]{2}{*}{4} & A & 0.1465 & 0.0270 & 0.0300 & 0.8484 & -11.42 & 5.1250 & 5.1528 & 5.1499 \\
\hline & B & 0.0689 & 0.0137 & 0.0152 & 0.5693 & -9.80 & 3.8750 & 3.8472 & 3.8500 \\
\hline \multirow[t]{4}{*}{5} & A & 0.1048 & 0.0197 & 0.0220 & 0.7076 & -10.98 & 4.8571 & 4.8203 & 4.8288 \\
\hline & B & 0.0796 & 0.0182 & 0.0198 & 0.7587 & -13.01 & 4.5714 & 4.7447 & 4.7140 \\
\hline & C & 0.0431 & 0.0078 & 0.0088 & 0.2970 & -7.30 & 3.2857 & 3.0754 & 3.1042 \\
\hline & $\mathrm{D}$ & 0.1717 & 0.0302 & 0.0334 & 0.8980 & -11.25 & 5.2857 & 5.3598 & 5.3532 \\
\hline \multirow[t]{2}{*}{6} & A & 0.0900 & 0.0150 & 0.0169 & 0.5359 & -9.64 & 4.6000 & 4.4110 & 4.4410 \\
\hline & B & 0.0535 & 0.0140 & 0.0151 & 0.6337 & -13.78 & 4.4000 & 4.5862 & 4.5569 \\
\hline \multirow[t]{3}{*}{7} & A & 0.1505 & 0.0275 & 0.0305 & 0.8599 & -11.41 & 5.1538 & 5.1965 & 5.1916 \\
\hline & B & 0.0640 & 0.0127 & 0.0142 & 0.5415 & -9.44 & 3.7692 & 3.6934 & 3.7019 \\
\hline & C & 0.0903 & 0.0173 & 0.0189 & 0.6698 & -10.37 & 4.1538 & 4.2204 & 4.2130 \\
\hline \multirow[t]{3}{*}{8} & A & 0.1665 & 0.0295 & 0.0327 & 0.8889 & -11.35 & 5.2500 & 5.3195 & 5.3116 \\
\hline & B & 0.0469 & 0.0088 & 0.0099 & 0.3791 & -7.93 & 3.4167 & 3.2602 & 3.2824 \\
\hline & C & 0.1001 & 0.0208 & 0.0225 & 0.8180 & -12.59 & 4.6667 & 4.8409 & 4.8122 \\
\hline \multirow[t]{5}{*}{9} & A & 0.1020 & 0.0191 & 0.0213 & 0.6911 & -10.77 & 4.8182 & 4.7552 & 4.7683 \\
\hline & B & 0.0753 & 0.0178 & 0.0194 & 0.7610 & -13.16 & 4.5455 & 4.7312 & 4.6976 \\
\hline & C & 0.0542 & 0.0098 & 0.0111 & 0.4005 & -8.09 & 3.5455 & 3.4001 & 3.4197 \\
\hline & D & 0.0741 & 0.0148 & 0.0164 & 0.6103 & -9.95 & 4.0000 & 4.0099 & 4.0123 \\
\hline & $\mathrm{E}$ & 0.1427 & 0.0263 & 0.0292 & 0.8361 & -11.33 & 5.0909 & 5.1039 & 5.1024 \\
\hline \multirow[t]{4}{*}{10} & A & 0.1116 & 0.0205 & 0.0229 & 0.7492 & -10.72 & 4.9231 & 4.8802 & 4.8855 \\
\hline & B & 0.0908 & 0.0194 & 0.0211 & 0.7942 & -11.90 & 4.6154 & 4.7573 & 4.7318 \\
\hline & $C$ & 0.0204 & 0.0040 & 0.0042 & -0.0555 & -4.42 & 1.6923 & 1.5412 & 1.5685 \\
\hline & D & 0.2003 & 0.0325 & 0.0359 & 0.9145 & -10.11 & 5.3846 & 5.4105 & 5.4072 \\
\hline \multirow[t]{3}{*}{11} & A & 0.1660 & 0.0295 & 0.0327 & 0.8874 & -11.29 & 5.2500 & 5.3192 & 5.3114 \\
\hline & B & 0.0469 & 0.0088 & 0.0099 & 0.3708 & -7.90 & 3.4167 & 3.2604 & 3.2825 \\
\hline & C & 0.1002 & 0.0201 & 0.0225 & 0.8189 & -12.59 & 4.6667 & 4.8412 & 4.8126 \\
\hline \multirow[t]{3}{*}{12} & A & 0.1087 & 0.0207 & 0.0231 & 0.7411 & -11.00 & 4.9000 & 4.8964 & 4.9002 \\
\hline & B & 0.0835 & 0.0183 & 0.0200 & 0.7621 & -12.36 & 4.6000 & 4.7487 & 4.7227 \\
\hline & C & 0.0361 & 0.0055 & 0.0065 & 0.1365 & -5.25 & 3.0000 & 2.7096 & 2.7540 \\
\hline \multirow[t]{5}{*}{13} & A & 0.0926 & 0.0162 & 0.0182 & 0.5834 & -10.10 & 4.6667 & 4.5298 & 4.5544 \\
\hline & B & 0.0579 & 0.0150 & 0.0161 & 0.6872 & -13.82 & 4.4444 & 4.6590 & 4.6225 \\
\hline & $C$ & 0.0633 & 0.0143 & 0.0156 & 0.6362 & -12.46 & 4.4444 & 4.5560 & 4.5402 \\
\hline & D & 0.0413 & 0.0066 & 0.0075 & 0.2048 & -6.13 & 3.1111 & 2.8458 & 2.8780 \\
\hline & $\mathrm{E}$ & 0.1768 & 0.0308 & 0.0341 & 0.9094 & -11.01 & 5.3333 & 5.4095 & 5.4049 \\
\hline \multirow[t]{3}{*}{14} & A & 0.0896 & 0.0137 & 0.0155 & 0.4869 & -8.97 & 4.5000 & 4.2740 & 4.2997 \\
\hline & B & 0.0507 & 0.0124 & 0.0135 & 0.5684 & -13.31 & 4.3333 & 4.4568 & 4.4357 \\
\hline & C & 0.0453 & 0.0123 & 0.0132 & 0.5881 & -14.60 & 4.3333 & 4.5796 & 4.5365 \\
\hline
\end{tabular}

\footnotetext{
a $V B$-EC obtained with the STO-6G basis set.

b $V B-E C^{*}$ obtained with the pseudo- $\pi$ approach.
}

Although the differences between the VB-EC and EC values are very small and there is a very good correlation between them, in some cases the two indices can lead to significantly different conclusions concerning chemical properties of a given system. This can be found in the case of linear polyacenes (molecules 2, 6 and 14). According to the $V B-E C$ values the inner rings in these systems are more aromatic than the terminal rings, whereas the $E C$ values predict the opposite trend. The so-called "anthracene problem" [57] refers to the phenomena that different indices predict different order of aromaticity in linear polyacenes. Some aromaticity indices (e.g. ef, $S C I$ ) predict that the terminal rings are more aromatic than the inner rings in linear polyacenes, whereas some other indices (e.g. HOMA, NICS) predict the opposite.

The correlation between the original $E C$ values and some other aromaticity indices has been already examined [58]. It was found that EC is in good correlation with HOMA and NICS. In the present work the correlation between the $V B-E C$ values and the other employed indices was studied for the examined benzenoid systems (Fig. 4). We focus on the correlation of VB-EC with HOMA, NICS(1), ef and SCI indices, and provide the correlation between the $V B-E C$ and $S C I^{N A O}$ in the Supplementary material (Fig. S3) because two differently calculated SCIs used in this work provide essentially the same information on the local aromaticity. As can be seen from Fig 4, the best, but not particularly good linear correlation is found between $V B-E C$ and HOMA (correlation coefficient is 0.9733 ), and the worst one is between VB-EC and NICS(1) (correlation coefficient of -0.7946 only). A detailed analysis of the presented correlations showed that the data-points are grouped into four clusters pertaining to hexagonal rings with different annelation types (Fig. 5). The four annelation modes that can be found in the studied molecules (1-14) are depicted in Fig. 6. Note that in the benzenoid molecules twelve different annelation modes are possible [59]. As can be seen from the data given in Table 5, the correlations of the $V B-E C$ with the other indices are much better within each of the four clusters of data-points. The best correlations were found between the $V B-E C$ and HOMA, and VB-EC and SCI. Both the VB-EC 


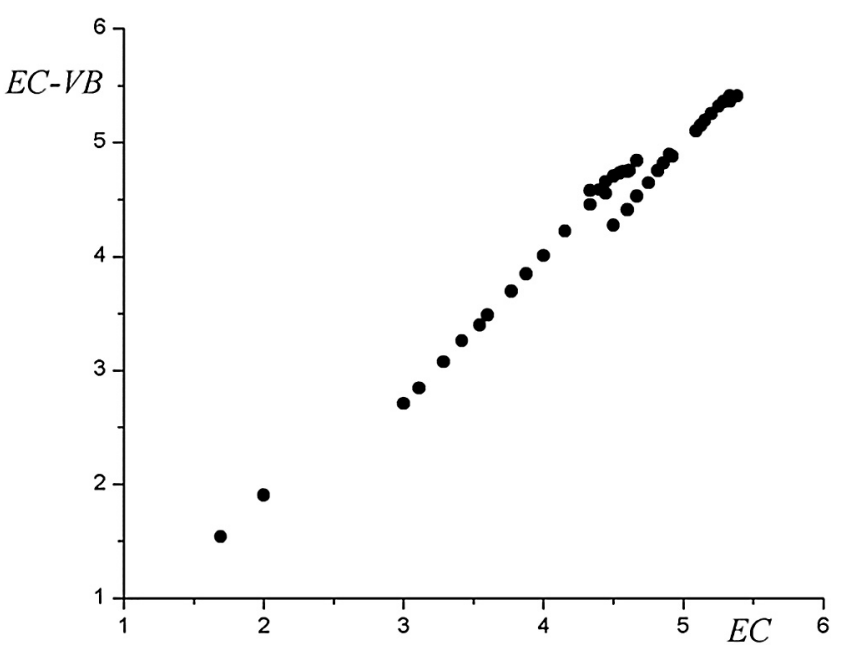

Fig. 3. Correlation between the $V B-E C$ and $E C$ values calculated for the symmetrynonequivalent rings in the studied benzenoid molecules (1-14); the correlation coefficient is $R=0.9914$.

and $S C I$ provide the measure of $\pi$-electrons delocalization in the considered ring, and therefore the good agreement between these two quantities is not surprising. On the other hand, the found correlation between $V B-E C$ and HOMA can be understood by com-

a)

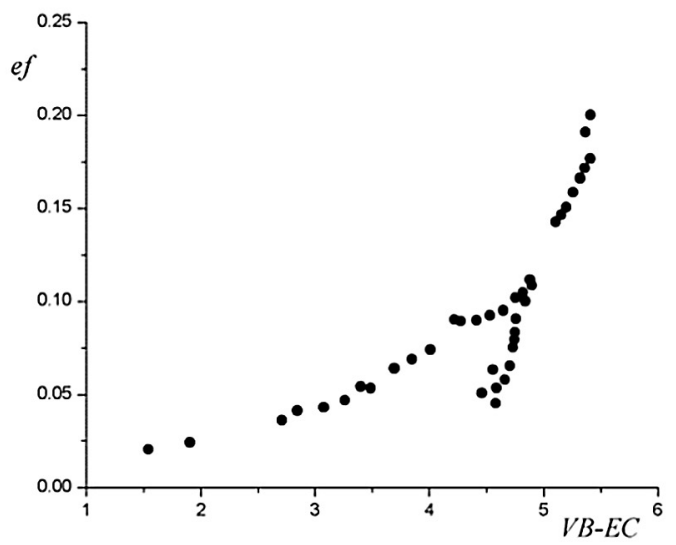

c)

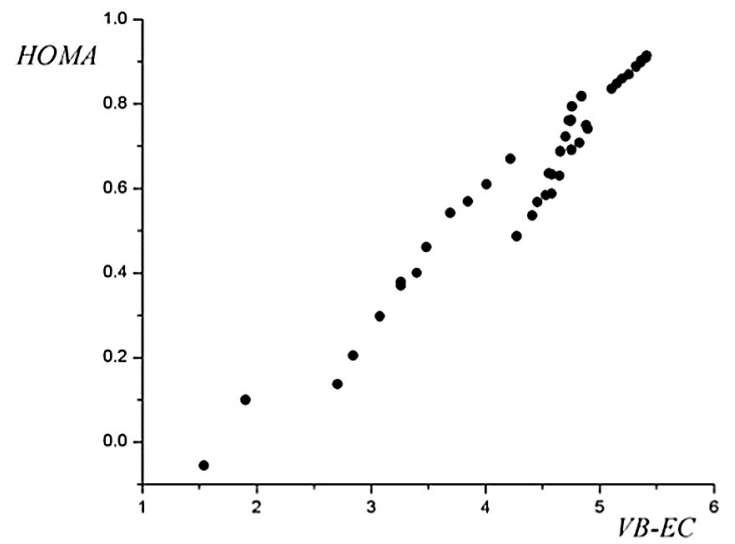

paring Eqs. (13) and (17). Indeed, as the Pauling bond order can be used for calculating carbon-carbon bond lengths [43,59], the VB-EC values actually measure in an implicit way the "geometry" manifestations of aromaticity.

\subsection{Aza derivatives of naphthalene}

Although the EC-method can be applied to any conjugated polycyclic hydrocarbons, in most of its applications the six-membered rings of benzenoid hydrocarbons were considered [28,29,58]. Only in a few studies the $E C$ of non-benzenoid systems were examined $[60,61]$. The $E C$ approach has as limitation that it cannot be applied for monocyclic conjugated systems. For instance, the $E C$ cannot be used to measure the aromaticity of the transition state in the Diels-Alder reaction [62]. In addition, it has been already recognized that the original $E C$-values in heteroatom-containing molecules are the same as in the parent hydrocarbon molecules, and a new approach aimed at overcoming this failure of the $E C$-method has been proposed [63]. In this section we show that the $V B-E C$ values can quantify the local aromaticity in heterocyclic conjugated molecules, and this is exemplified in a series of aza derivatives of naphthalene (Fig. 2). Aromaticity of the examined aza derivatives of naphthalene has been much studied in the past $[64,65]$. As can be seen from Kekule structures of the studied aza derivatives of naphthalene (Fig. 7), the Randić-Balaban EC-method is not able to distinguish any differences in aromaticity of symmetry unique rings $\mathrm{A}$ and $\mathrm{B}$. On the other hand, our $\mathrm{VB}-E C$ method is capable to

b)

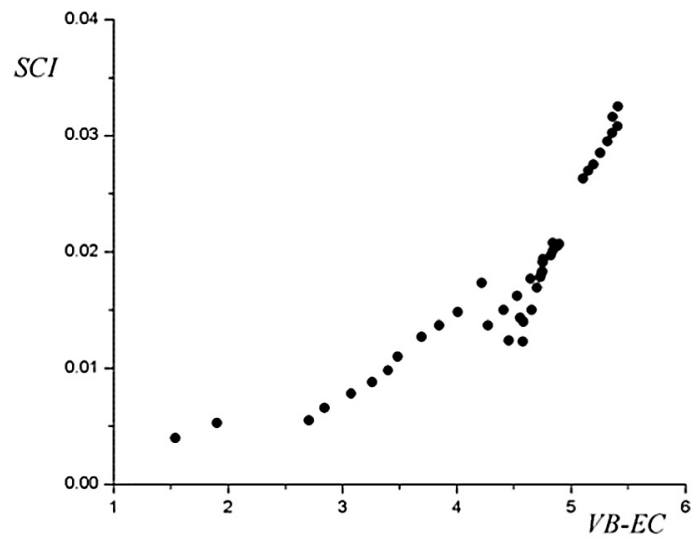

d)

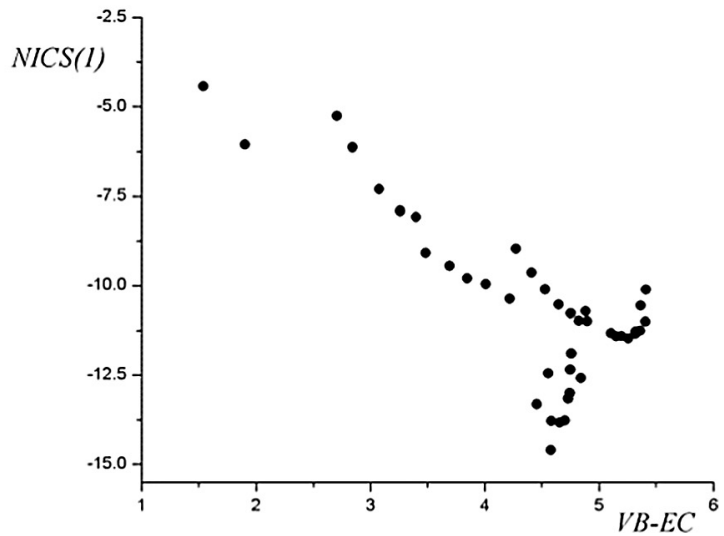

Fig. 4. Dependence of the values of different aromaticity indices for 43 symmetry unique hexagonal rings in molecules 1-14 on the VB-EC values obtained with the STO-6G basis set: (a) ef vs. VB-EC; (b) $S C I$ vs. VB-EC; (c) HOMA vs. VB-EC and (d) NICS(1) vs. VB-EC. 

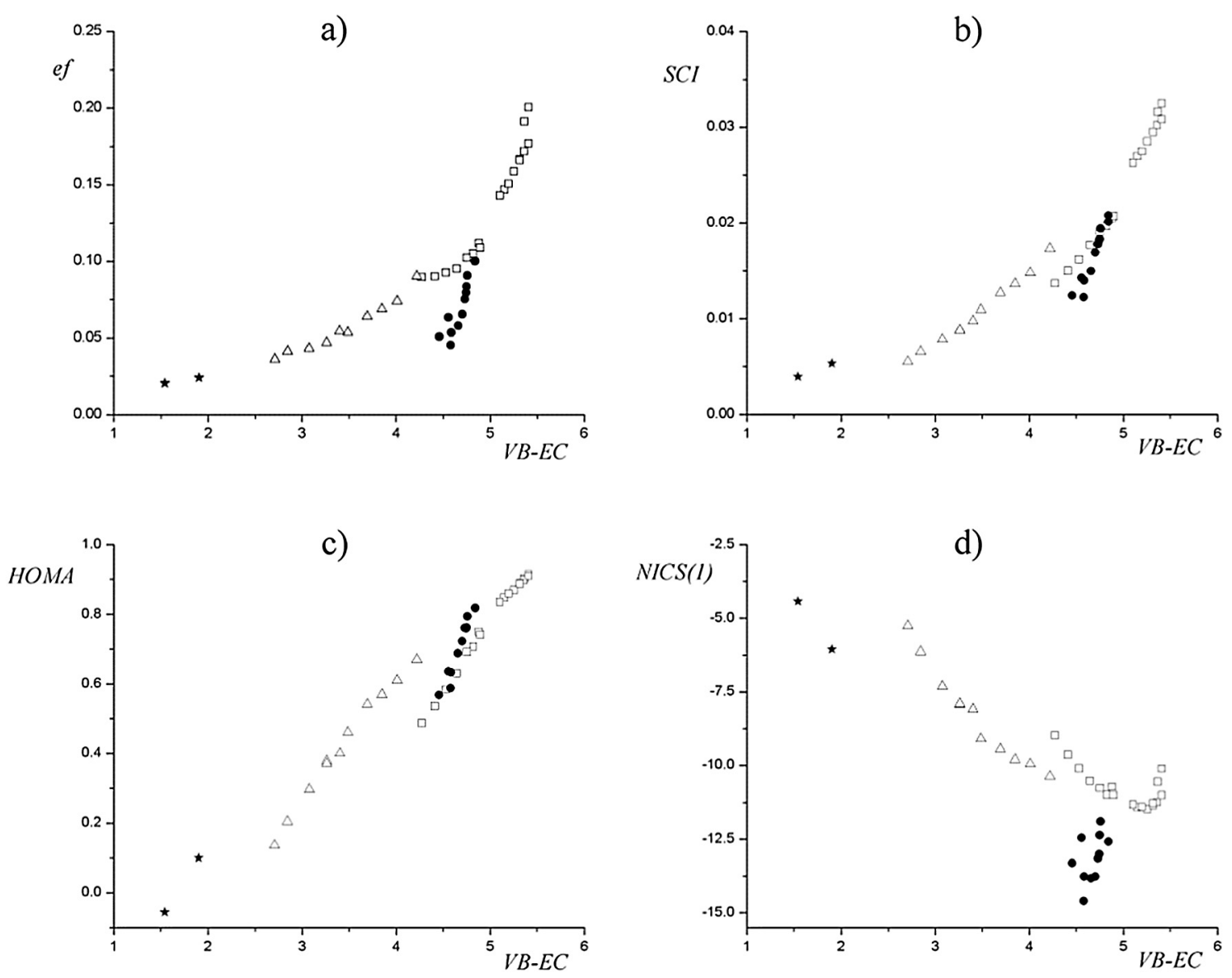

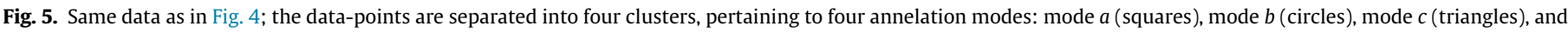
mode $d$ (asterisks) (cf. Fig. 6).

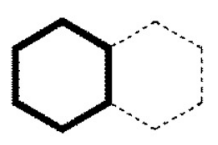

$a$<smiles>C1CCC2C[C@H]3CCCCC3C[C@@H]2CC1</smiles>

$b$<smiles>C1CCC2C(C1)CCC1CCCCC12</smiles>

C<smiles>C1CCC2C(C1)C1CCCCC1C1CCCCC21</smiles>

$d$

Fig. 6. The four different annelation modes of hexagonal rings that can be found in the studied benzenoid molecules 1-14.

Table 5

Correlation coefficients for the relations between different aromaticity indices and $V B-E C$ within the clusters of data-points pertaining to corresponding annelation modes (cf. Figs. 5 and 6).

\begin{tabular}{|c|c|c|c|}
\hline & \multicolumn{3}{|c|}{ Annelation mode } \\
\hline & $a$ & $b$ & $c$ \\
\hline ef & 0.9458 & 0.9027 & 0.9714 \\
\hline$S C I$ & 0.9878 & 0.9565 & 0.9932 \\
\hline$S C I^{N A O}$ & 0.9877 & 0.9551 & 0.9941 \\
\hline HOMA & 0.9954 & 0.9740 & 0.9933 \\
\hline $\operatorname{NICS}(1)$ & -0.7108 & 0.4849 & -0.9733 \\
\hline
\end{tabular}

assess differences in local aromaticity of rings A and B in the studied aza derivatives. The Coulson-Chirwing weights for the reference naphthalene compound and its aza derivatives 15-22 are displayed in Table 6. The Kekulé structure $\mathrm{k}_{2}$ (Fig. 7) comes out with the largest weight for all studied systems. Since Kekule struc-<smiles>c1ccc2ccccc2c1</smiles><smiles>c1ccc2ccccc2c1</smiles><smiles>c1ccc2ccccc2c1</smiles>

Fig. 7. Kekulé structures of naphthalene and of all its aza derivatives (Fig. 2) and the numbering of the sites in naphthalene where nitrogen atoms can be positioned.

ture $\mathrm{k}_{2}$ give the symmetric distribution of $\pi$-electrons, the difference in aromaticity of rings $A$ and $B$ comes from different VB weights of the structures $k_{1}$ and $k_{3}$. In monoaza $(15,16)$ and in almost all diaza derivatives in which both nitrogen atoms are in the same ring (18-20), the Kekulé structure $\mathrm{k}_{1}$ has a somewhat higher weight than the Kekule structure $\mathrm{k}_{3}$, thus a smaller $V B-E C$ value for nitrogen-containing ring $A$ than for ring $B$. The diaza 
Table 6

Coulson-Chirgwin weights of Kekulé structures of naphthalene and its aza derivatives obtained with the 6-311G(d,p) basis set (Fig. 7).

\begin{tabular}{llll}
\hline Comp. & $\mathrm{k}_{1}$ & $\mathrm{k}_{2}$ & $\mathrm{k}_{3}$ \\
\hline Naphthalene & 0.2664 & 0.4672 & 0.2664 \\
$\mathbf{1 5}$ & 0.2675 & 0.4757 & 0.2568 \\
$\mathbf{1 6}$ & 0.2715 & 0.4794 & 0.2491 \\
$\mathbf{1 7}$ & 0.2376 & 0.4589 & 0.3035 \\
$\mathbf{1 8}$ & 0.2719 & 0.4886 & 0.2395 \\
$\mathbf{1 9}$ & 0.2727 & 0.4867 & 0.2406 \\
$\mathbf{2 0}$ & 0.3182 & 0.5129 & 0.1689 \\
$\mathbf{2 1}$ & 0.2494 & 0.4884 & 0.2623 \\
$\mathbf{2 2}$ & 0.2480 & 0.4930 & 0.2590 \\
\hline
\end{tabular}

derivatives $\mathbf{2 1}$ and $\mathbf{2 2}$ with one nitrogen atom on each ring display weights very similar to naphthalene, and all three compounds consequently come out with very similar VB-EC values.

The calculated aromaticity indices for the studied heterocyclic systems are presented in Table 7. Except for the ef-values, all other indices indicate a very small difference in aromaticity of the two rings in the studied molecules. As can be seen, the $V B-E C$ is capable to assess those sophisticate changes of the local aromaticity. It can be observed that the $V B-E C, S C I$ and $N I C S(1)$ values provide very similar conclusions on the local aromaticity distribution in the studied aza naphthalenes. Only in the case of 19 the $V B-E C$ and $S C I$ do not agree, whereas the VB-EC and NICS(1) give opposite predictions in 21. In half of the studied systems $(\mathbf{1 7}, \mathbf{2 0}, \mathbf{2 1}, \mathbf{2 2})$ the results of the $H O M A$ and $V B-E C$ go along, but not for 15, 16, 18 and 19. It should be pointed out that in the previous study [65], it has been shown that the HOMA does not agree with the other aromaticity indices in aza naphthalenes. This can be attributed to the parametrization scheme used in the HOMA calculations, which fails to properly describe the bond lengths alternation in the studied heterocyclic molecules. On the other hand, the ef and $V B-E C$ values give opposite predictions, except for $\mathbf{1 7}$, for which according to all indices ring $\mathrm{A}$ is more aromatic than $\mathrm{B}$. The same conclusions can be deduced by examining the correlations between the $V B-E C$ and the other aromaticity indices for the studied aza naphthalenes (Fig. S4 in the Supplementary material). It can be seen that the best correlations were found in the cases of SCI and NICS(1). Interestingly, the $V B-E C$ is significantly better correlated with the $S C I^{N A O}$ than with the $S C I$ obtained from the Mulliken population scheme (see Table 8).
Table 8

Correlation coefficients for the relations between different aromaticity indices and $V B-E C$ of the hexagonal rings in aza derivatives of naphthalene (15-22).

\begin{tabular}{ll}
\hline & $R$ \\
\hline ef & 0.3373 \\
$S C I$ & 0.7947 \\
SCI & \\
HOMA & 0.9611 \\
NICS $(1)$ & 0.6068 \\
\end{tabular}

\section{Conclusions}

In this paper a new measure of local aromaticity based on ab initio VB calculations in combination with Kekule structures was introduced. This VB-EC approach can be considered as a more accurate version of the original $E C$ method that is based on Kekule structures with the crude hypothesis of identical weights for the different types of Kekule structures. For the studied benzenoid molecules, the $V B-E C$ and $E C$ values come out impressively close, with differences not exceeding 0.3 electrons at most. The main disagreement between the $V B-E C$ and $E C$ was found for linear polyacenes, for which the $V B-E C$ method predicts that the inner rings are more aromatic than the terminal ones, whereas the $E C$ method give the opposite prediction. Besides, it was shown that the basis set size, different definitions of VB structure weights, and different types of VB orbitals do not significantly influence the calculated $V B-E C$ values. In addition, even the pseudo- $\pi$ based $V B-E C$ can provide the same information on the local aromaticity as the $V B-E C$ obtained from regular VB calculations. Such VB-EC indices could therefore be easily determined for quite large systems from weights coming from a pseudo- $\pi$ calculation, without much computational effort. The original $E C$-values in heteroatom-containing molecules are the same as in parent hydrocarbon molecules. In the present work, for a series of aza derivatives of naphthalene it was shown how the $V B-E C$ quantity can overcome this disadvantage of the $E C$ method. The calculated $V B-E C$ values were compared with several other aromaticity indices that are in common use, and it was found that the $V B-E C$ results are very close to the results of HOMA and $S C I$ indices. The good agreement between the $V B-E C$ and HOMA index for benzenoid molecules was rationalized, by expressing $V B-E C$ in terms of the modified Pauling bond order. Bearing in mind that the Pauling bond order can be used in

Table 7

ef, SCI, SCI NAO , HOMA, NICS(1),EC, VB-EC for the examined aza derivatives of naphthalene (Fig. 2)

\begin{tabular}{|c|c|c|c|c|c|c|c|c|}
\hline Comp. & Ring & ef & $S C I$ & $S C I^{N A O}$ & HOMA & $\operatorname{NICS}(1)$ & $E C$ & $V B-E C$ \\
\hline Naphthalene & A & 0.1211 & 0.0238 & 0.0264 & 0.7845 & -11.51 & 5.000 & 5.000 \\
\hline 15 & $\begin{array}{l}\text { A } \\
\text { B }\end{array}$ & $\begin{array}{l}0.2361 \\
0.1547\end{array}$ & $\begin{array}{l}0.0230 \\
0.0238\end{array}$ & $\begin{array}{l}0.0259 \\
0.0262\end{array}$ & $\begin{array}{l}0.8238 \\
0.7947\end{array}$ & $\begin{array}{l}-11.18 \\
-11.51\end{array}$ & $\begin{array}{l}5.000 \\
5.000\end{array}$ & $\begin{array}{l}4.9893 \\
5.0107\end{array}$ \\
\hline 16 & $\begin{array}{l}\text { A } \\
\text { B }\end{array}$ & $\begin{array}{l}0.2844 \\
0.1232\end{array}$ & $\begin{array}{l}0.0217 \\
0.0240\end{array}$ & $\begin{array}{l}0.0257 \\
0.0265\end{array}$ & $\begin{array}{l}0.8276 \\
0.8096\end{array}$ & $\begin{array}{l}-11.20 \\
-11.57\end{array}$ & $\begin{array}{l}5.000 \\
5.000\end{array}$ & $\begin{array}{l}4.9776 \\
5.0224\end{array}$ \\
\hline 17 & $\begin{array}{l}\text { A } \\
\text { B }\end{array}$ & $\begin{array}{l}0.3535 \\
0.0503\end{array}$ & $\begin{array}{l}0.0257 \\
0.0222\end{array}$ & $\begin{array}{l}0.0276 \\
0.0245\end{array}$ & $\begin{array}{l}0.8847 \\
0.7980\end{array}$ & $\begin{array}{l}-12.04 \\
-11.51\end{array}$ & $\begin{array}{l}5.000 \\
5.000\end{array}$ & $\begin{array}{l}5.0659 \\
4.9341\end{array}$ \\
\hline 18 & $\begin{array}{l}\text { A } \\
\text { B }\end{array}$ & $\begin{array}{l}0.4656 \\
0.1515\end{array}$ & $\begin{array}{l}0.0222 \\
0.0239\end{array}$ & $\begin{array}{l}0.0250 \\
0.0263\end{array}$ & $\begin{array}{l}0.8710 \\
0.8236\end{array}$ & $\begin{array}{l}-10.73 \\
-11.57\end{array}$ & $\begin{array}{l}5.000 \\
5.000\end{array}$ & $\begin{array}{l}4.9676 \\
5.0324\end{array}$ \\
\hline 19 & $\begin{array}{l}\text { A } \\
\text { B }\end{array}$ & $\begin{array}{l}0.2633 \\
0.0359\end{array}$ & $\begin{array}{l}0.0249 \\
0.0234\end{array}$ & $\begin{array}{l}0.0259 \\
0.0256\end{array}$ & $\begin{array}{l}0.8466 \\
0.8061\end{array}$ & $\begin{array}{l}-11.14 \\
-11.50\end{array}$ & $\begin{array}{l}5.000 \\
5.000\end{array}$ & $\begin{array}{l}4.9679 \\
5.0321\end{array}$ \\
\hline 20 & $\begin{array}{l}\text { A } \\
\text { B }\end{array}$ & $\begin{array}{l}0.4402 \\
0.1272\end{array}$ & $\begin{array}{l}0.0213 \\
0.0259\end{array}$ & $\begin{array}{l}0.0227 \\
0.0286\end{array}$ & $\begin{array}{l}0.7733 \\
0.8741\end{array}$ & $\begin{array}{l}-10.60 \\
-11.97\end{array}$ & $\begin{array}{l}5.000 \\
5.000\end{array}$ & $\begin{array}{l}4.8507 \\
5.1493\end{array}$ \\
\hline 21 & $\begin{array}{l}\text { A } \\
\text { B }\end{array}$ & $\begin{array}{l}0.2590 \\
0.4633\end{array}$ & $\begin{array}{l}0.0232 \\
0.0225\end{array}$ & $\begin{array}{l}0.0260 \\
0.0256\end{array}$ & $\begin{array}{l}0.8461 \\
0.8376\end{array}$ & $\begin{array}{l}-11.14 \\
-11.24\end{array}$ & $\begin{array}{l}5.000 \\
5.000\end{array}$ & $\begin{array}{l}5.0129 \\
4.9871\end{array}$ \\
\hline 22 & $\begin{array}{l}\text { A } \\
\text { B }\end{array}$ & $\begin{array}{l}0.3323 \\
0.6707\end{array}$ & $\begin{array}{l}0.0232 \\
0.0223\end{array}$ & $\begin{array}{l}0.0262 \\
0.0256\end{array}$ & $\begin{array}{l}0.8410 \\
0.8334\end{array}$ & $\begin{array}{l}-11.31 \\
-11.20\end{array}$ & $\begin{array}{l}5.000 \\
5.000\end{array}$ & $\begin{array}{l}5.0109 \\
4.9891\end{array}$ \\
\hline
\end{tabular}


calculations of carbon-carbon bond lengths, the $V B$-EC can also assess the geometrical aspects of aromaticity.

\section{Acknowledgements}

The authors thank Professor Philippe C. Hiberty for helpful suggestions and discussions, and Professor Wei Wu for making his XMVB 2.1 code available to us. S. R. and M. A. thank the Serbian Ministry of Education and Science for partial support of this work through grant No. 174033.

\section{References}

[1] M.K. Cyrański, Energetic aspects of cyclic $\pi$-electron delocalization: evaluation of the methods of estimating aromatic stabilization energies, Chem. Rev. 105 (2005) 3773-3811, http://dx.doi.org/10.1021/cr0300845.

[2] J. Poater, M. Duran, M. Solà, B. Silvi, Theoretical evaluation of electron delocalization in aromatic molecules by means of atoms in molecules (AIM) and electron localization function (ELF) topological approaches, Chem. Rev. 105 (2005) 3911-3947, http://dx.doi.org/10.1021/cr030085x.

[3] F. Feixas, E. Matito, J. Poater, M. Sola, Quantifying aromaticity with electron delocalisation measures, Chem. Soc. Rev. 44 (2015) 6434-6451, http://dx.doi. org/10.1039/C5CS00066A.

[4] L. Pauling, G.W. Wheland, The nature of the chemical bond. V. The quantum mechanical calculation of the resonance energy of benzene and naphthalene and the hydrocarbon free radicals, J. Chem. Phys. 1 (1933) 362-374.

[5] M.J.S. Dewar, C. De Llano, Ground states of conjugated molecules. XI. Improved treatment of hydrocarbons, J. Am. Chem. Soc. 91 (1969) 789-795, http://dx.doi. org $/ 10.1021 / \mathrm{ja0} 032 \mathrm{a} 001$.

[6] B.A. Hess, L.J. Schaad, Hückel molecular orbital $\pi$ resonance energies. New approach, J. Am. Chem. Soc. 93 (1971) 305-310, http://dx.doi.org/ 10.1021/ja00731a003.

[7] I. Gutman, M. Milun, N. Trinajstić, Graph theory and molecular orbitals. 19. Nonparametric resonance energies of arbitrary conjugated systems, J. Am. Chem. Soc. 99 (1977) 1692-1704, http://dx.doi.org/10.1021/ja00448a002.

[8] J. Aihara, A new definition of Dewar-type resonance energies, J. Am. Chem. Soc. 98 (1976) 2750-2758, http://dx.doi.org/10.1021/ja00426a013.

[9] M. Randić, Aromaticity of polycyclic conjugated hydrocarbons, Chem. Rev. 103 (2003) 3449-3606, http://dx.doi.org/10.1021/cr9903656.

[10] W.C. Herndon, Resonance energies of aromatic hydrocarbons. Quantitative test of resonance theory, J. Am. Chem. Soc. 95 (1973) 2404-2406, http://dx.doi.org/ $10.1021 / \mathrm{ja00788a073.}$

[11] W.C. Herndon, M.L. Ellzey, Resonance theory. V. Resonance energies of benzenoid and nonbenzenoid $\pi$ systems, J. Am. Chem. Soc. 96 (1974) 66316642, http://dx.doi.org/10.1021/ja00828a015.

[12] Y. Mo, S.D. Peyerimhoff, Theoretical analysis of electronic delocalization, J. Chem. Phys. 109 (1998) 1687-1697.

[13] Y. Mo, Geometrical optimization for strictly localized structures, J. Chem. Phys. 119 (2003) 1300-1306.

[14] Y. Mo, P. von R. Schleyer, An energetic measure of aromaticity and antiaromaticity based on the Pauling-Wheland resonance energies, Chem. A Eur. J. 12 (2006) 2009-2020, http://dx.doi.org/10.1002/chem.200500376.

[15] T.M. Krygowski, Crystallographic studies of inter- and intramolecular interactions reflected in aromatic character of $\pi$-electron systems, J. Chem. Inf. Comput. Sci. 33 (1993) 70-78, http://dx.doi.org/10.1021/ci00011a011.

[16] T.M. Krygowski, H. Szatylowicz, O.A. Stasyuk, J. Dominikowska, M. Palusiak, Aromaticity from the viewpoint of molecular geometry: application to planar systems, Chem. Rev. 114 (2014) 6383-6422, http://dx.doi.org/10.1021/ cr400252h.

[17] Z. Chen, C.S. Wannere, C. Corminboeuf, R. Puchta, P. von R. Schleyer, Nucleusindependent chemical shifts (NICS) as an aromaticity criterion, Chem. Rev. 105 (2005) 3842-3888, http://dx.doi.org/10.1021/cr030088+.

[18] J.A.N.F. Gomes, R.B. Mallion, Aromaticity and ring currents, Chem. Rev. 101 (2001) 1349-1384, http://dx.doi.org/10.1021/cr990323h.

[19] A. Ciesielski, T.M. Krygowski, M.K. Cyrański, M.A. Dobrowolski, A.T. Balaban, Are thermodynamic and kinetic stabilities correlated? A topological index of reactivity toward electrophiles used as a criterion of aromaticity of polycyclic benzenoid hydrocarbons, J. Chem. Inf. Model. 49 (2009) 369-376, http://dx. doi.org/10.1021/ci800400b.

[20] Y. Mo, The resonance energy of benzene: a revisit, J. Phys. Chem. A 113 (2009) 5163-5169, http://dx.doi.org/10.1021/jp808941h.

[21] Y. Mo, P.C. Hiberty, P. von R. Schleyer, How to properly compute the resonance energy within the ab initio valence bond theory: a response to the ZHJVL paper, Theor. Chem. Acc. 127 (2010) 27-38, http://dx.doi.org/10.1007/s00214010-0794-7.

[22] M. Zielinski, R.W.A. Havenith, L.W. Jenneskens, J.H. van Lenthe, A comparison of approaches to estimate the resonance energy, Theor. Chem. Acc. 127 (2010) 19-25, http://dx.doi.org/10.1007/s00214-010-0793-8.

[23] S. Shaik, P.C. Hiberty, A Chemist's Guide to Valence Bond Theory, WileyInterscience, New York, 2008.

24] W. Wu, P. Su, S. Shaik, P.C. Hiberty, Classical valence bond approach by modern methods, Chem. Rev. 111 (2011) 7557-7593, http://dx.doi.org/10.1021/ cr100228r.

[25] D.J. Klein, Aromaticity via Kekule structures and conjugated circuits, J. Chem. Educ. 69 (1992) 691-694, http://dx.doi.org/10.1021/ed069p691.

[26] E. Clar, The Aromatic Sextet, John Wiley \& Sons Ltd., London, 1972.

[27] M. Solà, Forty years of Clar's aromatic $\pi$-sextet rule, Front. Chem. 1 (2013) 22 http://dx.doi.org/10.3389/fchem.2013.00022.

[28] A.T. Balaban, M. Randić, Partitioning of $\pi$-electrons in rings of polycyclic benzenoid hydrocarbons. 2. Catacondensed coronoids, J. Chem. Inf. Comput. Sci. 44 (2003) 50-59, http://dx.doi.org/10.1021/ci0341641.

[29] M. Randić, A.T. Balaban, Partitioning of $\pi$-electrons in rings of polycyclic conjugated hydrocarbons. Part 1: Catacondensed benzenoids, Polycycl. Aromat. Compd. 24 (2004) 173-193, http://dx.doi.org/10.1080/ 10406630490432792

[30] M. Randić, Graph theoretical approach to $\pi$-electron currents in polycyclic conjugated hydrocarbons, Chem. Phys. Lett. 500 (2010) 123-127, http://dx.doi. org/10.1016/j.cplett.2010.09.064.

[31] M. Randić, Algebraic Kekulé formulas for benzenoid hydrocarbons, J. Chem. Inf Comput. Sci. 44 (2004) 365-372, http://dx.doi.org/10.1021/ci0304167.

[32] I. Gutman, D. Vukičević, A. Graovac, M. Randić, Algebraic Kekulé structures of benzenoid hydrocarbons, J. Chem. Inf. Comput. Sci. 44 (2004) 296-299, http:// dx.doi.org/10.1021/ci030417z.

[33] I. Gutman, S. Bosanac, Quantitative approach to Hückel rule the relations between the cycles of a molecular graph and the thermodynamic stability of a conjugated molecule, Tetrahedron 33 (1977) 1809-1812. http:// www.sciencedirect.com/science/article/pii/0040402077840635.

[34] I. Gutman, Cyclic conjugation energy effects in polycyclic $\pi$-electron systems Monatsh. Chem. 136 (2005) 1055-1069, http://dx.doi.org/10.1007/s00706005-0295-x.

[35] T.M. Krygowski, M. Cyrański, Separation of the energetic and geometric contributions to the aromaticity of $\pi$-electron carbocyclics, Tetrahedron 52 (1996) 1713-1722, http://dx.doi.org/10.1016/0040-4020(95)01007-6.

[36] M. Giambiagi, M.S. de Giambiagi, C.D. dos Santos Silva, A.P. de Figueiredo, Multicenter bond indices as a measure of aromaticity, Phys. Chem. Chem. Phys. 2 (2000) 3381-3392, http://dx.doi.org/10.1039/B002009P.

[37] P. Bultinck, R. Ponec, S. Van Damme, Multicenter bond indices as a new measure of aromaticity in polycyclic aromatic hydrocarbons, J. Phys. Org. Chem. 18 (2005) 706-718, http://dx.doi.org/10.1002/poc.922.

[38] P. von R. Schleyer, C. Maerker, A. Dransfeld, H. Jiao, N.J.R. van E. Hommes, Nucleus-independent chemical shifts: a simple and efficient aromaticity probe, J. Am. Chem. Soc. 118 (1996) 6317-6318, http://dx.doi.org/ $10.1021 /$ ja960582d.

[39] B.H. Chirgwin, C.A. Coulson, The electronic structure of conjugated systems. VI, Proc. R. Soc. London. Ser. A. Math. Phys. Sci. 201 (1950), 196 LP-209, <http:// rspa.royalsocietypublishing.org/content/201/1065/196.abstract>.

[40] P. Löwdin, A quantum mechanical calculation of the cohesive energy, the interionic distance, and the elastic constants of some ionic crystals, Ark. För Mat. Astron. Och Fys. 35A (1947) 1-10.

[41] G.A. Gallup, J.M. Norbeck, Population analyses of valence-bond wavefunctions and BeH2, Chem. Phys. Lett. 21 (1973) 495-500, http://dx.doi.org/10.1016/ 0009-2614(73)80292-1.

[42] I. Gutman, T. Morikawa, S. Narita, On the $\pi$-electron content of bonds and rings in benzenoid hydrocarbons, Zeitschrift Für Naturforsch. A 59 (2004) 295-298, http://dx.doi.org/10.1515/zna-2004-4-516.

[43] L. Pauling, L.O. Brockway, J.Y. Beach, The dependence of interatomic distance on single bond-double bond resonance, J. Am. Chem. Soc. 57 (1935) 27052709, http://dx.doi.org/10.1021/ja01315a105.

[44] R. Bochicchio, R. Ponec, A. Torre, L. Lain, Multicenter bonding within the AIM theory, Theor. Chem. Acc. 105 (2001) 292-298, http://dx.doi.org/10.1007/ s002140000236.

[45] W. Heyndrickx, P. Salvador, P. Bultinck, M. Solà, E. Matito, Performance of 3Dspace-based atoms-in-molecules methods for electronic delocalization aromaticity indices, J. Comput. Chem. 32 (2011) 386-395, http://dx.doi.org/ $10.1002 /$ jcc. 21621.

[46] P. Bultinck, M. Rafat, R. Ponec, B. Van Gheluwe, R. Carbó-Dorca, P. Popelier, Electron delocalization and aromaticity in linear polyacenes: atoms in molecules multicenter delocalization index, J. Phys. Chem. A 110 (2006) 7642-7648, http://dx.doi.org/10.1021/jp0609176.

[47] J.P. Foster, F. Weinhold, Natural hybrid orbitals, J. Am. Chem. Soc. 102 (1980) 7211-7218, http://dx.doi.org/10.1021/ja00544a007.

[48] M.J. Frisch, G.W. Trucks, H.B. Schlegel, G.E. Scuseria, M.A. Robb, J.R. Cheeseman, G. Scalmani, V. Barone, B. Mennucci, G.A. Petersson, H. Nakatsuji, M. Caricato, X. Li, H.P. Hratchian, A.F. Izmaylov, J. Bloino, G. Zheng, J.L. Sonnenberg, M Hada, M. Ehara, K. Toyota, R. Fukuda, J. Hasegawa, M. Ishida, T. Nakajima, Y. Honda, O. Kitao, H. Nakai, T. Vreven, J.A. Montgomery, J.E. Peralta, F. Ogliaro, M. Bearpark, J.J. Heyd, E. Brothers, K.N. Kudin, V.N. Staroverov, R. Kobayashi, J Normand, K. Raghavachari, A. Rendell, J.C. Burant, S.S. Iyengar, J. Tomasi, M. Cossi, N. Rega, J.M. Millam, M. Klene, J.E. Knox, J.B. Cross, V. Bakken, C. Adamo, 
J. Jaramillo, R. Gomperts, R.E. Stratmann, O. Yazyev, A.J. Austin, R. Cammi, C. Pomelli, J.W. Ochterski, R.L. Martin, K. Morokuma, V.G. Zakrzewski, G.A. Voth, P. Salvador, J.J. Dannenberg, S. Dapprich, A.D. Daniels, Farkas, J.B. Foresman, J. V Ortiz, J. Cioslowski, D.J. Fox, Gaussian 09, Revision B.01, Gaussian Inc., Wallingford CT, 2009.

[49] K. Wolinski, J.F. Hinton, P. Pulay, Efficient implementation of the gaugeindependent atomic orbital method for NMR chemical shift calculations, J. Am Chem. Soc. 112 (1990) 8251-8260, http://dx.doi.org/10.1021/ja00179a005.

[50] J.R. Cheeseman, G.W. Trucks, T.A. Keith, M.J. Frisch, A comparison of models fo calculating nuclear magnetic resonance shielding tensors, J. Chem. Phys. 104 (1996) 5497-5509, http://dx.doi.org/10.1063/1.471789.

[51] P.W. Fowler, E. Steiner, Pseudo- $\pi$ currents: rapid and accurate visualisation of ring currents in conjugated hydrocarbons, Chem. Phys. Lett. 364 (2002) 259 266, http://dx.doi.org/10.1016/S0009-2614(02)01244-7.

[52] P. Bultinck, Critical analysis of the local aromaticity concept in polyaromatic hydrocarbons, Faraday Discuss. 135 (2007) 347-365, http://dx.doi.org 10.1039/B609640A

[53] L. Song, Z. Chen, F. Ying, J. Song, X. Chen, P. Su, Y. Mo, Q. Zhang, W. Wu, XMVB 2.1: An Ab Initio Non-Orthogonal Valence Bond Program, Xiamen University, Xiamen 361005, China, 2015.

[54] Z. Chen, F. Ying, X. Chen, J. Song, P. Su, L. Song, Y. Mo, Q. Zhang, W. Wu, XMVB 2.0: a new version of Xiamen valence bond program, Int. J. Quantum Chem. 115 (2015) 731-737, http://dx.doi.org/10.1002/qua.24855.

[55] L. Song, Y. Mo, Q. Zhang, W. Wu, XMVB: a program for ab initio nonorthogonal valence bond computations, J. Comput. Chem. 26 (2005) 514-521, http://dx. doi.org/10.1002/jcc.20187.

[56] Z. Chen, X. Chen, W. Wu, Nonorthogonal orbital based N-body reduced density matrices and their applications to valence bond theory. I. Hamiltonian matrix elements between internally contracted excited valence bond wave functions, J. Chem. Phys. 138 (2013) 164119, http://dx.doi.org/10.1063/1.4801631.
[57] P.W. Fowler, W. Myrvold, The "Anthracene Problem": closed-form conjugatedcircuit models of ring currents in linear polyacenes, J. Phys. Chem. A 115 (2011) 13191-13200, http://dx.doi.org/10.1021/jp206548t.

[58] A.T. Balaban, M. Randić, Partitioning of $\pi$-electrons in rings of polycyclic conjugated hydrocarbons: Part 6. Comparison with other methods for estimating the local aromaticity of rings in polycyclic benzenoids, J. Math. Chem. 37 (2005) 443-453, http://dx.doi.org/10.1007/s10910-004-1114-z.

[59] I. Gutman, S.J. Cyvin, Introduction to the Theory of Benzenoid Hydrocarbons, Springer-Verlag, Berlin, 1989.

[60] A.T. Balaban, M. Randić, Partitioning of $\pi$-electrons in rings of polycyclic conjugated hydrocarbons. 5. Nonalternant compounds, J. Chem. Inf. Comput. Sci. 44 (2004) 1701-1707, http://dx.doi.org/10.1021/ci049842y.

[61] I. Gutman, B. Furtula, A Kekulé structure basis for phenylenes, J. Mol. Struct. THEOCHEM. $770 \quad$ (2006) 67-71, http://dx.doi.org/10.1016/j. theochem.2006.05.025.

[62] E. Matito, J. Poater, M. Duran, M. Solà, An analysis of the changes in aromaticity and planarity along the reaction path of the simplest Diels-Alder reaction. Exploring the validity of different indicators of aromaticity, J. Mol. Struct. THEOCHEM. 727 (2005) 165-171, http://dx.doi.org/10.1016/j. theochem.2005.02.020

[63] I. Gutman, Partitioning of $\pi$-electrons in rings of polycyclic conjugated molecules containing heteroatoms, MATCH Commun. Math. Comput. Chem. 56 (2006) 345-356.

[64] M. Mandado, N. Otero, R.A. Mosquera, Local aromaticity study of heterocycles using n-center delocalization indices: the role of aromaticity on the relative stability of position isomers, Tetrahedron 62 (2006) 12204-12210, http://dx. doi.org/10.1016/j.tet.2006.10.022.

[65] A. Mohajeri, M. Shahamirian, П-electron delocalization in aza derivatives of naphthalene and indole, Comput. Theor. Chem. 976 (2011) 19-29, http://dx. doi.org/10.1016/j.comptc.2011.07.036. 